\title{
DO LOBO E DO HUMANO: UM OLHAR ANTROPOLÓGICO SOBRE A RELAÇÃO HUMANO-ANIMAL EM DUAS OBRAS DE JACK LONDON
}

\section{OF WOLF AND HUMAN: AN ANTHROPOLOGICAL LOOK TO HUMAN- NATURE RELATIONSHIP IN TWO NOVELS BY JACK LONDON}

\author{
Hugo de Carvalho Ferreira ${ }^{1}$
}

10.21665/2318-3888.v5n10p138-156

\section{RESUMO}

O presente artigo tem como objetivo discutir duas obras de Jack London - $O$ chamado da floresta e Caninos Brancos - como ilustração para uma reflexão teórica no que tange à relação humano-animal. $\mathrm{O}$ desenvolvimento do texto é realizado com base nas obras mencionadas, bem como críticas feitas a estas, e comparações com a literatura etnológica. $\mathrm{O}$ argumento apresentado é que os mesmos contos podem ser abordados por chaves explicativas distintas, expressando diferentes concepções de humano e natureza, selvagem e doméstico, aprendizado e instinto. Por fim, sugere-se que estas duas histórias possam ser compreendidas enquanto ilustrações de tendências recentes da etnologia, buscando superar a dicotomia natureza e cultura, bem como simetrizar a relação humano-animal.

Palavras-chave: Relação humano-animal. Antropologia e Natureza. Tim Ingold. Natureza e cultura. Antropologia Social. Jack London.

\footnotetext{
${ }^{1}$ Doutorando em Cultural Sudies na Europa Universität Viadriana. Mestre em Saúde Pública e Meio Ambiente pela Fundação Oswaldo Cruz (2013). E-mail: hugo.decf@yahoo.com.br.
} 


\section{ABSTRACT}

This article aims to discuss two books written by Jack London - The call of the wild and White Fang - as an illustration for a theoretical reflection about human-animal relations. The article is based on the books mentioned above, as well as on critiques addressed to them, and also comparisons with the ethnological literature. The argument is that these stories may be seen through different lens and expressing different conceptions of human and nature or learning and instinct. Therefore, it suggests that these two stories might be comprehended as illustrations for recent trends in ethnology, in order to overcome the nature/culture dichotomy and bring symmetry to the human-animal relation.

Keywords: Human-animal relation. Anthropology and Nature. Tim Ingold. Nature and culture. Social Anthropology. Jack London. 


\section{Introdução}

Jack London (1876 - 1916) foi um reconhecido escritor estadunidense, autor de dezenas de livros e clássicos da literatura. Nascido na Califórnia, London é conhecido por ter viajado por vários anos e vivido diversas experiências tais como a corrida do ouro no Alaska ou a bordo de navios no Pacífico, andanças essas que constituem matéria-prima abundante para suas histórias e contos. No presente artigo, aborda-se em particular duas obras de Jack London: O chamado da floresta (2003), no original The call of the wild [1903]; e Caninos Brancos (2004), no original White Fang [1906]. No primeiro livro mencionado, London conta a história de um cão que vivia na Califórnia, que após ser sequestrado e levado ao Alaska se vê perante o desafio de viver em um ambiente hostil e desconhecido; no último, o escritor narra a história de Caninos Brancos, um lobo que é trazido para o seio de uma comunidade indígena. A luta pela vida, o aprendizado e a experiência são temas marcantes em ambos os livros, e assim, estes representam lados opostos de uma mesma moeda: em O chamado, a passagem de uma vida "doméstica" em uma casa na Califórnia para a "selva" alaskiana; em Caninos, da vida "selvagem" na floresta para um ambiente "doméstico" em uma comunidade humana. Desde já, vale frisar que os termos selvagem e doméstico estão em aspas uma vez que são conceitos caros à etnologia, e por isso, não se quer aqui abordá-los como dados. Ao contrário, pretende-se exatamente problematizar os mesmos ao longo do artigo.

Nesse sentido, tem-se como objetivo discutir as obras de London como ilustração ou ponto focal, servindo de base para uma reflexão teórica no que tange à relação humanoanimal. $\mathrm{O}$ argumento apresentado é que os mesmos contos podem ser abordados por modelos distintos, expressando diferentes concepções de humano e natureza ou aprendizado e instinto - desde uma interpretação cartesiana do "animal-máquina" até a percepção do animal como pessoa. Assim, sugiro que estas duas histórias possam ser compreendidas enquanto ilustrações de tendências recentes da etnologia, associadas a antropólogos como Tim Ingold e Eduardo Kohn. O desenvolvimento do texto será feito com base em escritos de Jack London, bem como críticas feitas às obras e comparações com a literatura etnológica. 
Dito isso, o artigo apresenta a seguinte estrutura: inicialmente, introduz-se as já citadas obras de Jack London, para então recuperar sucintamente algumas críticas e interpretações sobre as mesmas; em seguida, faz-se uma discussão sobre as noções de aprendizagem e instinto com o intuito de desconstruir a visão cartesiana do animal como máquina, e na sequência, problematizar a noção de animais como pessoas; a partir daí, aborda-se o tema da relação-humano animal, e de que modo algumas tendências contemporâneas podem dialogar com as obras de Jack London aqui trabalhadas.

\section{O chamado da floresta}

O livro é protagonizado por Buck - um cão de "boa" linhagem, forte e vigoroso, o qual tem um lugar de destaque na mansão do juiz Miller, na Califórnia. É Buck quem escolta as filhas do juiz durante os passeios no bosque, e quem brinca no jardim com os netos. Durante o inverno, aconchegava-se junto à lareira na biblioteca do juiz. Um cão fiel, acostumado à vida doméstica e à soberania entre os demais cães da propriedade.

Entretanto, naquele tempo havia em curso a corrida do ouro no Alaska. Milhares de homens deixavam suas casas para tentar a sorte no extremo norte. A empreitada gerou uma demanda de cães para puxar trenós, e assim, um mercado ilegal de cães prosperou. E foi então que Buck teve sua vida transformada: sequestrado por um dos empregados do juiz, viu-se em poucos dias rumo ao Alaska. Pela primeira vez experimentou a violência dos humanos - seres que até então se apresentavam como justos e amigáveis.

Chegando ao Alaska, um novo mundo se abre para Buck. Era o fim do ócio, do aconchego e da comida farta. Sua vida passa a ser um constante desafio, onde deve aprender a lidar com as intempéries da região, com os estranhos humanos ao seu redor e com os demais cães puxadores de trenó (e suas hostilidades). Apesar das dificuldades, Buck conquista grande reputação entre os humanos e os cães.

Posteriormente, Buck se torna propriedade de outro humano, John Thornton, um homem justo e respeitoso. A relação com Thornton se torna particularmente afetuosa. Desde que foi raptado de sua morada na Califórnia, pela primeira vez Buck desenvolve amor por 
outro ser humano. Ao mesmo tempo, Buck percebe a presença de criaturas selvagens ao longo da floresta, a qual o perturba e atrai constantemente.

Em um dia fatídico, o acampamento de Thornton é atacado por índios, episódio que culmina na morte de seu querido dono. Buck se vê então sem qualquer laço com a humanidade, e decide se juntar ao grupo de cães que os acompanhavam, para então vir a experimentar a vida na floresta. Por fim, o cão volta ao local da morte de Thornton, reconhecendo a emoção de sua ligação com esse humano. Mas já não havia o que fazer, e assim, Buck resolve atender ao "chamado da floresta" e viver com um grupo de lobos da região.

\section{Caninos Brancos}

Neste livro, London escreve a antítese da história de Buck. A obra trata de "Caninos Brancos", meio lobo, meio cão, nascido e crescido na vida selvagem. Ainda enquanto filhote, ao lado de sua mãe (uma cadela que outrora era domesticada), o jovem lobo vivia o desafio da vida selvagem, da luta pelo alimento e por proteção.

Num dado dia, o lobo e sua mãe são encontrados por um grupo de indígenas, e assim, mãe e filho são incorporados ao seio da tribo. Caninos brancos teve de aprender a confiar nos homens, a entender o sistema de obediência e recompensa, e aos poucos ganhou a mútua lealdade de seu dono. O lobo também se vê diante de outros animais, e assim, precisa compreender as relações e hierarquias em jogo. Por exemplo, é somente após repetidos eventos punitivos que ele compreende que as galinhas não devem ser incomodadas. Além disso, com o status de recém-chegado, este tem de conquistar seu espaço perante os cães da tribo, lutando por sua porção de alimento e pela predileção dos humanos (os "deuses-homens", como Caninos Brancos se refere).

No entanto, ainda que Caninos Brancos esteja se aclimatando à vida com os humanos, um certo sentimento selvagem ainda o perturba. Em uma ocasião, Caninos Brancos decide voltar para a floresta. Porém, após poucos dias este se vê com medo e inseguro. Ele percebe que está demasiadamente conectado aos humanos, e dessa maneira, decide 
voltar para a vida doméstica. Posteriormente, Caninos Brancos passa a ter um novo dono (Scott) que se empenha em domá-lo e ensinar certos comandos básicos. Eventualmente, Caninos Brancos salva a vida de Scott e assim ganha a gratidão e reconhecimento de sua família humana, e ao fim do livro, se encontra em uma casa aconchegante na Califórnia, tornando-se o leal companheiro da mesma.

\section{Os "nature-fakers"}

Em 1903, um artigo publicado pelo cientista natural John Burroughs desencadeou o que ficou conhecido na mídia estadunidense como "a controvérsia dos naturalistas" (HRIBAL, 2007). Em suma, criticava-se uma série de escritores e suas obras baseadas nas perspectivas dos animais. A crítica se baseava em uma suposta descrição falsa e ilusória destes animais, acusando os escritores de ignorância e distorção das verdades da natureza. Entre eles estava Jack London e seu conto sobre Buck. Segundo a crítica, os comportamentos animais seriam narrados por Jack London como racionais e inteligentes, embora estes não fossem mais do que o resultado do mais perfeito "instinto". A capacidade de raciocínio e escolha seriam comportamentos humanos, e London estaria "antropomorfizando" os animais.

Em 1907, o próprio presidente dos Estados Unidos àquela altura, Theodore Roosevelt, publicou uma nota criticando severamente essas "histórias fantásticas", onde os autores provavelmente sequer conheciam ou observaram os animais descritos. Roosevelt os denominou de "nature fakers", título que se tornou famoso durante a polêmica. Nas palavras de Roosevelt:

The modern "nature-faker" is of course an object of derision to every scientist worthy of the name, to every real lover of the wilderness, to every faunal naturalist, to every true hunter or nature lover. But it is evident that he completely deceives many good people who are wholly ignorant of wildlife. Sometimes he draws on his own imagination for his fictions; sometimes he gets them second-hand from irresponsible guides or trappers or Indians (ROOSEVELT, 1907).

Ainda que o presidente não mencione os nomes dos autores, a descrição dos contos não deixa dúvida que London fazia parte dos atacados, por exemplo, ao descrever a luta 
entre um buldogue (Buck) e um lobo (Spitz), e ainda outra passagem uma batalha entre um lince e um lobo (a mãe de Caninos Brancos).

Em 1908, Jack London publica uma resposta ao presidente, argumentando que Roosevelt e Burroughs teriam uma concepção mecanicista e antropocêntrica dos comportamentos animais. Um texto ácido, onde se dedica a mostrar a inadequação do "instinto" como explicação para os comportamentos animais - os cães também raciocinam, escreve London. O escritor baseia seus argumentos sobretudo em sua própria experiência pessoal com cães, descrevendo uma série de comportamentos que apontavam para o aprendizado e a inteligência, e não apenas a um suposto instinto puro (LONDON, 1908). E por fim conclui que, ainda que os animais apresentem uma capacidade de raciocínio mais simples, suas histórias não deveriam ser isoladas da história humana. Em suas próprias palavras:

[...] When Mr. Burroughs convincingly proves that every action of the dog is mechanical and automatic - then, by precisely the same arguments, can it be proved that the similar actions of man are mechanical and automatic. No, Mr. Burroughs, though you stand on the top of the ladder of life, you must not kick out that ladder from under your feet. You must not deny your relatives, the other animals. Their history is your history, and if you kick them to the bottom of the abyss, to the bottom of the abyss you go yourself (LONDON, 1908).

Curiosamente, a controvérsia dos naturalistas também resultou na fundação do Jack London Club, em 1918, com o intuito de defender aquilo que hoje se chamaria de "direitos dos animais" (HRIBAL, 2007). Não há dúvida de que no âmbito das ciências sociais contemporâneas, sobretudo na antropologia, a capacidade de aprendizagem (ou mesmo algo que se poderia chamar de "cultura") em alguns grupos animais apresenta certa aceitação entre pesquisadores (INGOLD, 2013; KOHN, 2007; NOSKE, 1993). Entretanto, a polêmica se faz presente na maioria dos campos científicos.

\section{Aprendizagem e instinto}

Na seção anterior, mostrou-se algumas reações em relação aos escritos de London, criticando a errônea naturalização dos animais, considerada má ciência. Nesta seção, 
diferentemente, apresenta-se um artigo que apóia as análises cognitivas de London, mas rechaça a suposta racionalidade nestes cães e lobos.

Tendo em vista a obra Caninos Brancos, Danielsson chama a atenção para as observações de London no que tange à comunicação interespecífica de lobos e cães, e entre eles e humanos: "Towards the end of the story, he also learns how to communicate with humans in different ways, and how to co-exist with a group of conspecifics, that is, other dogs" (DANIELSSON, 2013, p.125). Além disso, comenta Danielsson que London teria de fato observado minuciosamente o processo de aprendizagem dos cães e lobos, o qual viria a ser corroborado pelo posterior desenvolvimento da etologia:

\footnotetext{
Regardless of the methods London describes, they do result in the canine characters learning new skills. There are also a number of situations where the dog or wolf learns in other ways, through interaction with other canines or the environment, or when they learn from human behavior. Reading London's dog stories for their representations of cognitive processes shows how London makes use of his talent for observation[...](DANIELSSON, 2013, p. 124).
}

Todavia, ainda que Danielsson atribua crédito às observações de London, a autora remarca que London "antropomorfizaria" os animais em algumas passagens, conforme explicita ao escrever que "Even if he sometimes anthropomorphizes, loften in The Call of the Wild, less so in White Fang) there are also numerous descriptions that are recognizable as fair representations of canine cognition" (DANIELSSON, 2013, p.124). Ao que parece, a autora descreve o aprendizado de Caninos Brancos como fruto de reforço e punição. Em outros termos, o aprendizado do animal não seria pela razão, mas sim, como resposta a um estímulo, conforme pode ser reconhecido abaixo:

What London calls White Fang's inherited fear of the unknown is further
strengthened by experience when the cub tries to walk on water, falls in the
river, and almost drowns. This gives him "distrust in appearances", and we learn
that the cub "would have to learn the reality of a thing before he could put his
faith in it". Here London obviously anthropomorphizes, and extends the
argument too far, but most canid cubs or pups will have a similar experience
with water at some early point, and will learn at least that they cannot walk on
water, so the episode feels relevant at least (DANIELSSON, 2013, pp. 127-128).

Nesse sentido, seja à luz do início do século XIX ou da etologia moderna, a noção de razão e consciência dos animais em relação aos outros animais e aos humanos parece incômoda. 
De fato, é este o tema discutido por Ferreira (2016), o qual ilustra o modo como alguns comportamentos animais que não são diretamente ligados à sobrevivência e reprodução - e.g. lazer, altruísmo, compaixão, inveja, suicídio - são rotineiramente mecanizados sob o rótulo de "instinto" ou um certo determinismo genético. Com efeito, o Ocidente tem historicamente lidado com o pressuposto de que apenas os humanos são livres dos constrangimentos das necessidades biológicas e dos instintos. Essa relação é expressa pela oposição entre humanidade e animalidade, onde os humanos teriam a peculiaridade de, mesmo sendo animais, terem algo especial, i.e., razão, linguagem, etc. (INGOLD, 1995).

Além disso, é preciso ressaltar que esta dicotomia também é tradicionalmente postulada pelas ciências sociais, conforme pode se ver em autores renomados como Marx, Kroeber e Lévi-Strauss. Conforme a famosa passagem de Marx, ainda que uma abelha possa superar um arquiteto em termos técnicos, apenas o último é dotado de intelecto, possuindo o projeto de antemão em sua cabeça. Kroeber, em seu artigo sobre o "superorgânico", elimina qualquer possibilidade de uma socialidade "real" nãohumana, afirmando que os insetos sociais e alguns mamíferos não seriam sociais de fato (KROEBER, 1993). Na mesma esteira, Lévi-Strauss argumenta em As estruturas elementares do parentesco (1982) que há uma clara fronteira entre os humanos e os demais animais, gerada pela dobradiça das regras matrimoniais e da proibição do incesto.

Dito isso, tem-se a impressão de que, caso London descrevesse os comportamentos de cães e lobos de forma estática, excluindo a dimensão temporal da aprendizagem, esses poderiam ser lidos como ciência natural; na outra linha, caso os lobos falassem entre si e com os humanos, tal qual em Chapeuzinho Vermelho, estes seriam de fato figuras antropomórficas. Dito isso, parece que a polêmica surge quando a descrição de London não estabelece definitivamente se os lobos seriam criaturas instintivas ou humanos comunicativos/inteligentes, ciência ou fábula, natureza ou cultura. 


\section{A noção de pessoa e a relação humano-animal}

A discussão sobre a noção de pessoa remonta ao texto clássico de Marcel Mauss (2003). Em seu ensaio, Mauss ilumina os aspectos culturais/sociais daquilo que seria algo óbvio ou banal, a dizer, a noção de pessoa. Através de um estudo histórico e cultural sobre o estatuto da pessoa em diversas sociedades, Mauss mostra a particularidade da "pessoa" moderna. Em várias culturas, a pessoa é entendida como um título, um direito a personagens, e assim, o que entendemos hoje como um indivíduo biológico poderia não ser/possuir uma pessoa, ao passo que um outro indivíduo poderia possuir várias pessoas. Não é por acaso que a palavra pessoa deriva do latim persona, que significa "máscara" - na Roma Antiga a pessoa era vista como uma personagem, ligada ao nome e aos direitos de personalidade (e de fato, os escravos não possuíam um sobrenome, não eram "pessoas"). É somente com a filosofia/ciência moderna que se constitui a noção atual de pessoa, onde é compreendida na modernidade como uma unidade biológica/cognitiva resultante do processo de desenvolvimento humano e da mente humana. Dessa maneira, os indivíduos biológicos são suportes para a mente e a pessoa - cada corpo singular possui a sua própria pessoa singular.

Conforme já explicitado, Ingold (2000b) argumenta que no Ocidente os humanos seriam aqueles animais caracterizados por "algo mais". Somente os humanos são pessoas, e as únicas concessões a essa exceção são as fábulas e os animais de estimação, mas em ambos os casos os animais são quasi-pessoas. Não por acaso, ainda que os animais recebam nomes, normalmente seus nomes não são usuais, e muito menos são dotados de sobrenome. Por outro lado, os humanos são animais peculiares, apresentando ao mesmo tempo uma dimensão natural (fisiológica, instintiva) e cultural (razão, linguagem), sendo os únicos animais que também podem ser pessoas. E é por esse mesmo motivo que relações entre humanos e animais não são entendidas como sociais, dado que relações sociais "autênticas" seriam desempenhadas por pessoas. Com efeito, em Evolution and social life (1986), Ingold enfatiza esse ponto ao notar que apenas as sociedades humanas são objeto de estudo do sociólogo, dado que as sociedades animais para Durkheim (assim como Spencer) não são mais do que agregados de indivíduos "governados por uma predisposição inata" (INGOLD, 1986, p.228). 
Em última análise, para a ciência ocidental, pode-se dizer, as relações sociais (tanto as racionais quanto as "instintivas") são geralmente pensadas enquanto restritas ao âmbito intraespecífico, onde os animais apresentam relações sociais (ou "quasi-sociais", conforme muitos sociólogos clássicos) entre animais; os humanos apresentam relações sociais entre os humanos; e a relação entre animais e humanos seria uma relação de produção ou simbólica, orientada e dominada pelos humanos (NOSKE, 1993). Daí a própria expressão linguística antropocêntrica, onde os "humanos domesticaram tal espécie" ou "tal espécie foi domesticada pelos humanos" (vale notar a proximidade etimológica entre os termos "dominação", "domesticação", "domicílio" e "dono", derivados do latim "domus"). Como comenta Noske (1993) sobre a "questão animal", na concepção dominante de relação humano-animal, os animais são receptáculos da intenção humana, seja como parte de sua economia (alimento, transporte, etc.), seja como parte de um sistema simbólico-religioso (sacrifício, totemismo, etc.).

Portanto, historicamente, a relação humano-animal é pensada como uma relação entre sujeito e objeto. Essa questão fica evidente no texto From Trust to Domination: An Alternative History of Human-Animal Relations (2000a), onde Ingold comenta que há uma longa tradição no pensamento moderno que entende a relação de caça, o pastoreio e a indústria como etapas de um processo evolutivo da humanidade. No mesmo diapasão, essas etapas corresponderiam à passagem de um estado de natureza para a civilização. Assim, caçadores são compreendidos enquanto ainda pertencentes a um modo de vida natural, intocado. O humano civilizado é o ser humano que se emancipou da natureza, isto é, que se posiciona acima dos demais seres vivos por meio da razão e do intelecto. Por sua vez, a narrativa civilizada vê o mundo (e as plantas e animais) tendo a si mesma como referência: os seres não-humanos seriam classificados em "selvagens" e "domésticos", definidos em relação aos civilizados: o primeiro enquanto em estado natural, primordial ou primitivo; o segundo, enquanto parte integrante da esfera civilizatória. Vale notar a crítica de Noske à visão dominante da relação humano-animal (nessa citação a crítica é direcionada aos cientistas sociais):

It is curious that scientists who have learned to beware of the dangers of ethnocentrism so easily lapse into another kind of centrism - anthropocentrism. We are sadly stuck with two seemingly unrelated images: one of humankind 
and one of animalkind conveyed by two totally separate brands of science, the one typifying humans as social subjects, the other typifying animals as biological objects. The newly emerging discipline of human-animal relations will find this a formidable obstacle to overcome (NOSKE, 1993, p.190).

Nesse mesmo bojo teórico, o humano civilizado é aquele que desenvolveu a domesticação e a vida abundante. A domesticação está um passo à frente da caça e coleta, sendo fruto de um processo coevolutivo entre o humano e o animal. Por outro lado,o caçador e a caça representam uma relação antagônica, de corrida pela sobrevivência. Mas em nenhum dos casos há uma relação social: no primeiro, uma relação econômica, onde animais são fatores de produção; no segundo, um estado de guerra. Nos termos de Ingold:

Behind this opposition between the wild and the domestic there lies a much more fundamental metaphysical dualism - [...] This is the separation of two, mutually exclusive domains of being to which we attach the labels 'humanity' and 'nature'" (INGOLD, 2000a, p.63).

Em suma: há uma tradição dominante que reconhece o selvagem e o doméstico como categorias estanques, onde a diferença entre os animais selvagens e domésticos seria que os últimos estão em contato (e submissão) com os humanos há milhares de anos (INGOLD, 2000a). A relação entre os humanos e os animais domésticos não se trata de uma relação social, mas sim, biológica. Dessa forma, a domesticação é entendida como um processo coevolutivo, e assim, a transformação dos comportamentos individuais não requer aprendizado ou "cultura", mas sim, coevolução. Em poucas palavras, sendo os animais criaturas instintivas, a aprendizagem e a domesticação através da evolução biológica de longo prazo são explicações convenientes para o paradigma dominante.

Dito isso, é preciso ter em vista o caráter etnocêntrico da noção de pessoa discutida anteriormente, i.e., da noção de pessoa enquanto uma exclusividade humana condicionada por seu aparato cognitivo-biológico. Ao contrário, a noção de que animais são verdadeiramente pessoas é largamente encontrada em outros contextos culturais.

Não há dúvida, o trabalho de Viveiros de Castro (1996; 2002) sobre o perspectivismo ameríndio constitui material rico para uma desconstrução da singularidade humana ocidental. De acordo com o autor, os povos das terras baixas da América do Sul pensam a si e aos demais seres vivos enquanto humanos. A diferença visível entre os seres se 
daria simplesmente por uma diferença corporal, superficial, e de certa forma, "ilusória". Todos os seres fazem as mesmas coisas - caçam, comem, casam-se, bebem cauim, etc. - mas o modo como as coisas são vistas difere de acordo com a perspectiva (e o corpo) de um determinado ser. E assim, as noções de "natureza" e "cultura" se tornam estranhas para pensar o mundo numa chave ameríndia. Nas palavras do autor:

\begin{abstract}
Tipicamente, os humanos, em condições normais, veem os humanos como humanos, os animais como animais e os espíritos (se os veem) como espíritos; já os animais (predadores) e os espíritos vêem os humanos como animais (de presa), ao passo que os animais (de presa) vêem os humanos como espíritos ou como animais (predadores). Em troca, os animais e espíritos se vêem como humanos: apreendem-se como (ou se tornam) antropomorfos quando estão em suas próprias casas ou aldeias, e experimentam seus próprios hábitos e características sob a espécie da cultura - vêem seu alimento como alimento humano (os jaguares vêem o sangue como cauim, os mortos vêem os grilos como peixes, os urubus vêem os vermes da carne podre como peixe assado etc.), seus atributos corporais (pelagem, plumas, garras, bicos etc.) como adornos ou instrumentos culturais, seu sistema social como organizado do mesmo modo que as instituições humanas (com chefes, xamãs, festas, ritos etc.) [...] Em suma, os animais são gente, ou se vêem como pessoas. Tal concepção está quase sempre associada à idéia de que a forma manifesta de cada espécie é um mero envelope (uma "roupa") a esconder uma forma interna humana, normalmente visível apenas aos olhos da própria espécie ou de certos seres transespecíficos, como os xamãs. Essa forma interna é o espírito do animal: uma intencionalidade ou subjetividade formalmente idêntica à consciência humana, materializável, digamos assim, em um esquema corporal humano oculto sob a máscara animal (VIVEIROS DE CASTRO, 1996, p.117).
\end{abstract}

Dessa forma, neste contexto etnográfico a relação humano-animal é necessariamente entre pessoas.

\title{
6. Histórias alternativas sobre o selvagem e o doméstico
}

Entretanto, a relação entre humano-animal enquanto sujeit-objeto não corresponde ao que os próprios caçadores e donos de animais domésticos pensam e fazem. Por exemplo, na Amazônia, a etnografia de Philippe Erikson (2012) relata a presença intensa de animais familiarizados entre os Matis na Amazônia. A estes animais, reserva-se o termo "xerimbabos", referindo-se aos animais que foram incorporados à vida da aldeia (tais como pássaros e pequenos primatas). Vale dizer, sabe-se que na Amazônia indígena não existem tais noções como natureza e cultura, ao menos como no Ocidente. Assim, quando os xerimbabos são "domesticados" ou familiarizados, relata Erikson, há todo 
uma série de hábitos para que os xerimbabos continuem domésticos. Por exemplo, evitase a ingestão de vegetais selvagens já que estes poderiam desfamiliarizar os xerimbabos. Em todo caso, note-se que selvagem e doméstico não são estatutos naturais, mas uma condição contingente que pode ser revertida sob determinadas circunstâncias. A domesticidade é um processo, o qual requer trabalho e esforço, estando por isso em constante ameaça.

A relação humano-animal enquanto uma relação social também é observada em outras descrições. Por exemplo, entre os Cree, acredita-se que as renas selvagens se oferecem ao caçador (INGOLD, 2000a). A caça não é conquistada, mas sim, ofertada. Portanto, em ambos os exemplos, entre os caçadores e a caça não há uma luta cega pela sobrevivência. Conforme Ingold argumenta, embora variem quanto à forma, tanto as relações de caça como as domésticas implicam em uma relação social.

Em outro contexto etnográfico, Willerslev (2012) descreve a relação entre estes e a caça como "sedução" entre os caçadores Yukaghirs da Sibéria. Ressalte-se, diferentemente dos ocidentais, os Yukaghirs não pensam a humanidade como um dado natural. Ao contrário, humanos podem se tornar animais, animais em humanos, mortos em vivos, sendo o mundo marcado por uma "interminável continuidade de transformações" (WILLERSLEV, 2012, p. 62). Isso dito, percebe-se a importância da transformação a qual os caçadores se submetem com o intuito de se assemelhar e atrair a presa para fora da floresta. A teoria nativa é que, sendo a caçada um processo de sedução, esta requer um processo de metamorfose do caçador, e de certa maneira, um "devir caça" com o intuito de estabelecer uma relação com a mesma. Por essa razão, antes da caçada, conta Willerslev, os caçadores percorrem todo um conjunto de ritos e tabus, evitam odores humanos e se vestem com peles de animais.

Por fim, pode-se citar também a etnografia de Piers Locke (2017) com domadores de elefantes no Nepal. O próprio autor iniciou um treinamento como aprendiz de domador de elefantes, e segundo ele, a relação com o elefante foi necessariamente social. Constantemente Locke se via impelido a tocar o animal ou falar de uma determinada 
forma, e mais do que isso, compreender as reações e os sinais emitidos pelo elefante. No artigo, após descrever um de seus rituais de saudação ao animal, ele reconhece:

I came to realize that acts like these were not merely an aspect of the etiquette of human-elephant relations-they were also an implicit recognition of the elephant's autonomy, of their being-in-the-world, their capability to make their own decisions rather than just follow our commands (LOCKE, 2017, p. 363).

E por fim, conclui:

This intensely affective experience was so profoundly transformative that I was compelled to extend personhood itself: my apprenticeship became an endeavor in learning how to interact with a nonhuman intersubjectively, and to do so with communicative and empathetic efficacy. In embracing for myself the notion that elephants are like people too, through lived experience rather than philosophically reasoned conviction, [...] the question arises how to make anthropological sense of a challenge to key ontological assumptions about human uniqueness (LOCKE, 2017, p,369).

O que estes exemplos etnográficos mostram é que tanto os animais domésticos quanto os selvagens podem ser entendidos como pessoas. Conforme diz Kohn (2009) em uma entrevista com Philippe Descola, o reconhecimento de subjetividade em animais é na verdade quase universal, e assim, "a pergunta mais interessante parece ser o inverso, ou seja, como foi que os animais passaram a ser vistos como máquinas?".

\section{Uma relação social interespecífica?}

No artigo On reindeer and men (1974), Ingold discute a relação entre humanos e renas na Lapônia. O antropólogo inicia seu argumento defendendo que as renas possuem organização social e hierarquia, a qual é essencial para a relação com os humanos. No caso de grandes grupos de renas domésticas, a relação com o pastor se dá principalmente com as renas chave ou centrais ("core"). O mais interessante, é que as renas podem fugir e voltar de acordo com as vantagens obtidas através da relação com os humanos. Caso a segurança e alimentação ofertada não seja suficiente, estes podem vagar por outras regiões e se tornar "selvagens". Na mesma medida, as renas "selvagens" podem ser domesticadas à medida que reconhecem nos humanos uma chance de proteção e vantagens. Ingold reconhece a relação das renas entre si como 
autenticamente sociais - e da mesma maneira a relação entre as renas e os humanos. Em outros termos, não se trata de uma relação social natural ou biológica, mas de uma transação entre partes simétricas.

Para além dos exemplos etnográficos citados anteriormente, a percepção de que animais podem ser pessoas e se engajar autonomamente em uma relação interespecífica humano-animal (ou ao menos entre sujeitos distintos, já que um humano pode se animalizar para tal) vai de encontro à novas perspectivas antropológicas como "antropologia para além do humano" (INGOLD, 2013) ou para uma "antropologia da vida" (KOHN, 2007).

Nessa linha, pode-se argumentar aqui que "selvagem" e "doméstico" não estão associados às espécies enquanto categoria de descontinuação entre seres vivos. Ao longo da vida, lobos podem "caninar" e cães "lupinar". As fronteiras entre o selvagem e o doméstico não estão em milhares de anos de coevolução (ainda que a história biológica possa ter seu papel no que concerne à etologia), mas sim, numa relação social processual entre animais e humanos, continuamente construída através da prática.

É relativamente simples ver o incômodo que estas ideias causam. No modelo científicoocidental, pressupondo uma natureza espécie-específica, ter-se-ia que aceitar que animais possuem algo como "cultura" tal qual humanos. Daí, entende-se a razão porque estas abordagens concebem a domesticação enquanto processo de longo prazo: sendo os humanos os únicos capazes de se aculturar em um dado contexto social, animais seriam socializados apenas à medida de transformações biológicas, que por sua vez, repousam no paradigma neodarwinista de evolução pela seleção natural de variações morfogenéticas. O que se pode perceber é a noção de uma natureza da sociabilidade, a qual não deixa muito espaço para a noção de indivíduos em constante interação e negociação com outros (da mesma espécie ou não).

Dito isso, e voltando aos livros de London, vale lembrar que em um dado momento Caninos Brancos pensa em fugir de sua aldeia, e então, ao se sentir solitário, arrependese e volta para os humanos; no outro lado, ainda que Buck fosse atraído pela vida com os lobos, o cão permaneceu com o amado Thornton. E quando Buck já convivia com os 
lobos na floresta, ainda sim volta para o lugar onde Thornton havia morrido. Ora, seria contraditório um (agora) lobo (Buck) visitar seu antigo "dono", da mesma maneira que um cão (Caninos Brancos) fugir para a selva. Mas no fim, Buck decide ir com a matilha, e Caninos Brancos decide voltar para a aldeia ainda que se interesse pela selva. Assim, tende-se aqui a concordar com a interpretação de Ratelle sobre Caninos Brancos, onde a autora comenta a noção de formas "híbridas" de selvageria e domesticação.

The author himself invites an animality studies reading in which the canine is seen not as a fixed species but as a process of becoming whereby the subject loses itself within diverse forms of collectivity, shifting through diverse states of wildness, domesticity, and categorical hybridities (RATELLE, 2012, p.71).

\section{Considerações finais}

Em suma, sugere-se a seguinte hipótese: numa cosmologia (ocidental) onde as coisas são classificadas em natureza e cultura, selvagem e doméstico, não há lugar para esses "híbridos". Um animal é selvagem ou doméstico, não há muito espaço para devires "caninos e lupinos".

Conforme já explicitado anteriormente, a polêmica sobre os escritos de London emerge uma vez que os estatutos de selvagem e doméstico não são definitivamente estabelecidos. Talvez pela mesma razão, é interessante notar a dualidade da classificação crítica dada à autoria destas obras: de um lado, um nature-faker, um naturalista incompetente; do outro, um antropomorfizador, escritor de fábulas que se passam por realidade. Cães e lobos conscientes do mundo, de suas ações e dos sujeitos ao seu redor são, ou descrições toscas da realidade, ou ficção mal disfarçada.

Portanto, é preciso explicitar o problema teórico que as concepções dominantes sobre a natureza e a cultura impõe em relação à relação humano-animal. Os textos de London servem de ilustração e referência, tornando-se especialmente interessantes à luz das distintas interpretações e polêmicas geradas em torno das vidas de Buck e Caninos Brancos. 
Indubitavelmente, as fronteiras e estabilidade da humanidade cada vez mais se encontram sob pesada crítica, tal como se vê nas concepções teóricas de "antropologia para além da humanidade" e "antropologia da vida". A questão remanescente é: quais (e como) outras narrativas abrem espaço para a compreensão de uma sociabilidade animal para além dos instintos? Talvez seja mais do que hora de buscar visões alternativas às dicotomias natureza/cultura e instinto/aprendizagem, e para além disso, uma nova narrativa dos seres vivos e suas vidas sociais.

\section{Referências}

DANIELSSON, Karin Molander. White Fang as Ethological and Evolutionistic Bildungsroman. In: Litteraturochspråk, n.9, p. 121, 2013.

ERIKSON, Philippe. Animais demais...os xerimbabos no espaço doméstico matis (Amazonas). Anuário Antropológico, n.2, p. 15-32, 2012.

FERREIRA, Hugo de Carvalho. Uma reflexão sociológica sobre a interpretação de comportamentos animais. Revista Eletrônica de Ciências Sociais, n.22, p.1-16, 2016.

HRIBAL, Jason. Animals, agency, and class: Writing the history of animals from below. Human Ecology Review, v. 14, n. 1, p. 101-112, 2007.

INGOLD, Tim. On reindeer and men. Man, v. 9, n. 4, p. 523-538, 1974.

INGOLD, Tim. Evolutionand social life. Cambridge: Cambridge University Press, 1986.

INGOLD, Tim. Humanidade e animalidade. Revista Brasileira de Ciências Sociais, v.28, n.10, p. 39-53, 1995.

INGOLD, Tim. From Trust to Domination: An Alternative History of Human-Animal Relations. In: INGOLD, Tim. The perception of the environment: essays on livelihood, dwelling \& skill. London and New York: Routledge, 2000.

INGOLD, Tim. A circumpolar night'sdream. In: INGOLD, Tim. The perception of the environment: essays on livelihood, dwelling \& skill. London and New York: Routledge, 2000.

INGOLD, Tim. Anthropology Beyond Humanity. Suomen Antropologi: Journal of the Finnish Anthropological Society, v.38, n.2, 2013. 
LÉVI-STRAUSS, Claude. As estruturas elementares do parentesco. Petrópolis: Editora Vozes, 1982.

$\mathrm{KOHN}$, Eduardo. How dogs dream: Amazonian natures and the politics of transspecies engagement. American ethnologist, v. 34, n. 1, p. 3-24, 2007.

$\mathrm{KOHN}$, Eduardo. A conversationwith Philippe Descola. Tipití: Journal of the Society for the Anthropology of Lowland South America, v. 7, n. 2, p. 1, 2009.

KROEBER, Alfred. A Natureza da cultura. Lisboa: Edições 70, 1993.

LONDON, Jack. The other animals. 1908. Disponível em: <http://london.sonoma.edu/writings/Revolution/animals.html>. Acesso: 29 nov. 2017.

LONDON, Jack. O chamado da floresta. Porto Alegre: L\&PM, 2003.

LONDON, Jack. Caninos brancos. São Paulo: Editora Rideel, 2004.

MARX, Karl. O capital. São Paulo: Editora Nova Cultural, 1996.

MAUSS, Marcel. Sociologia \& Antropologia. São Paulo: Editora Cosac \&Naify, 2003. NOSKE, Barbara. The animal question in Anthropology: a commentary. Society and animals, v.1, n.2, 1993.

LOCKE, Piers. Elephants as persons, affective apprenticeship, and fieldwork with nonhuman informants in Nepal. HAU: Journal of Ethnographic Theory, v.7, n1, p.353-376, 2017.

RATELLE, Amy. The anthropomorphized animal in children's culture. Tese de Doutorado. York University. 2012.

ROOSEVELT, Theodore. Naturefakers. Everybody's Magazine, v. 17, n. 3, p. 427-30, 1907.

VIVEIROS DE CASTRO, Eduardo. Multinaturalismo e perspectivismo na América indígena. A inconstância da alma selvagem e outros ensaios de antropologia, p.345-399, 2002.

VIVEIROS DE CASTRO, Eduardo. Os pronomes cosmológicos e o perspectivismo ameríndio. Mana, 2(2), 115-144, 1996.

WILLERSLEV, Rane. Percepções da presa. Caça, sedução e metamorfose entre os Yukaghirs da Sibéria. Anuário Antropológico, n.2, p. 57-75, 2012. 